\title{
Efficacy of toric intraocular lens implantation with high corneal astigmatism within the United Kingdom's National Health Service
}

\author{
Andrew J. Swampillai ${ }^{1}$ Ali. Khanan Kaabneh ${ }^{1} \cdot$ Nabil E. Habib $^{1} \cdot$ Catriona Hamer ${ }^{2}$ Phillip J. Buckhurst ${ }^{2}$
}

Received: 8 August 2019 / Revised: 21 October 2019 / Accepted: 1 November 2019 / Published online: 16 December 2019

(c) The Author(s), under exclusive licence to The Royal College of Ophthalmologists 2019

\begin{abstract}
Objectives To determine the efficacy of toric intraocular lens (TIOL) implantation in cataract surgery patients with high levels of pre-operative corneal astigmatism and ocular co-morbidities in a state funded, National Health Service (NHS) hospital.

Methods Retrospective cohort study involving consecutive cases of TIOL implantation in cataract surgery with over 3.00DC of pre-operative corneal astigmatism. Subjects were implanted with the Tecnis TIOL (Abbot Medical Optics) with capsular tension ring stabilisation using the Callisto system (Carl Zeiss Meditec). Visual acuity and refraction were assessed at 4-6 weeks post-operatively. Vector analysis was used to calculate the intended refractive correction, surgically induced refractive correction (SIRC), correction ratio (CR), error of magnitude (EM) and error vector (EV).

Results Sixty-six eyes of forty-seven subjects aged 73.8 \pm 11.9 were included. Eyes with ocular co-morbidities included dry age-related macular degeneration $(n=13)$, amblyopia $(n=7)$, high myopia $(n=7)$, glaucoma $(n=6)$, previous corneal transplantation $(n=2)$, nanophthalmos $(n=2)$ and corneal scarring $(n=1)$. Pre-operative corneal astigmatism was $4.25 \pm$ 1.69DC (range 3.00-12.00), post-operative refractive astigmatism was $1.31 \pm 1.05 \mathrm{DC}$ (range 0.00-6.50DC) and postoperative unaided visual acuity was $0.25 \pm 0.19$ LogMAR. Vector analysis demonstrated an SIRC of 4.08 $\pm 1.39 \mathrm{DC}, \mathrm{CR}=$ $1.1 \pm 0.3, \mathrm{EM}-0.4 \pm 1.0$ and $\mathrm{EV}$ of $1.23 \pm 0.72$.

Conclusions The results demonstrate the efficacy of TIOL implantation in patients with high corneal astigmatism and provide strong evidence advocating their use in cataract surgery within a state funded hospital eye service. Refractive astigmatism was significantly lower than the pre-operative corneal astigmatism and a low error vector was achieved relative to the magnitude of correction.
\end{abstract}

\section{Introduction}

Cataract surgery is the most frequently performed surgical procedure in the National Health Service (NHS), with $\sim 350,000$ cataract extractions performed in England and Wales per annum [1]. Studies have demonstrated that around $11 \%$ of patients have over $2.00 \mathrm{D}$ of corneal astigmatism [2], this prevalence drops to around $2-4 \%$ when considering those with over 3.00D of corneal astigmatic error [3]. Wolffsohn et al. demonstrated that uncorrected

Phillip J. Buckhurst

phillip.buckhurst@plymouth.ac.uk

1 Royal Eye Infirmary, University Hospitals Plymouth NHS Trust, Plymouth, UK

2 School of Health Professions, Plymouth University, Plymouth, UK astigmatic error as low as 1.00D has a detrimental effect on both objective and the subjective perception of vision [4]. Each dioptre of refractive astigmatism reduces the chances of spectacle independence [5] and increases the lifetime costs of refractive correction for an individual [6].

Astigmatism correction at the time of cataract surgery can be achieved through manipulation of corneal shape: An incision placed along the steep corneal meridian will have a flattening effect and the larger the incision the greater the effect [7]. Higher magnitudes of flattening can be achieved by applying limbal relaxing incisions [8] or opposite clear corneal incisions [9]. However, on-axis incisions may be difficult or impossible to achieve in certain locations. Corneal relaxing incisions can result in post-operative glare, diplopia and fluctuation of refractive error due to proximity of the incisions to the corneal centre; furthermore, the technique requires pachymetry to be performed [10]. Limbal relaxing incisions entail risks such as exacerbating dry 
eye syndrome [11] as well acting as a potential site for infectious keratits [12]. All of these methods are influenced by surgical technique and are dependent on a variable corneal healing response. Consequently, it is not feasible to rely on these corneal techniques for correcting high levels of corneal astigmatism. Femtosecond laser incisions promise a more reliable technique with a more precise wound architecture, but the costs of these devices prohibit their widespread use within state funded systems such as the NHS in the United Kingdom (UK).

Toric Intraocular lenses (TIOLs) offer the opportunity to correct corneal astigmatism, without relying on the healing response of the cornea. Several studies have demonstrated the efficacy of TIOLS on subjects with low to moderate levels of corneal astigmatism [13, 14]. However few have demonstrated their efficacy in populations with high levels of astigmatism. Moreover, the majority of studies comprise of patient cohorts without any ocular co-morbidities and are not representative of refractive outcomes of cataract surgery in state funded healthcare. Within the UK, the National Institute for Health and Care Excellence evidence based guidelines form the bases of treatment recommendations within the NHS. The guidelines advocate the use of on-axis incisions and limbal relaxing incisions but not TIOLS citing a lack of evidence on the cost effectiveness of TIOL use within the UK [15]. Therefore, TIOLs are not commonly available within the NHS. The purpose of this study was to assess the use of a TIOL implantation in patients, typically presenting to the cataract service of a NHS hospital serving a large population.

\section{Methods}

Since November 2016, the Royal Eye Infirmary-University Hospitals Plymouth NHS trust (UHPNHST) has established a clear pathway to undertake cataract surgery with TIOL implant in patients with pre-operative keratometric cylinder of more than 3.00DC. Patients fulfilling the criteria are selected from local referral by community optometrists or from the pre-existing population under the hospital eye service, based on their keratometry measurements conducted at pre-operative assessment. The cut off level was based on the assumption that smaller degrees of astigmatism would be possible to manage with incisional techniques. The relatively low prevalence of corneal astigmatism greater than 3.00DC, ensured that demand for these TIOLs could be provided with a minimum impact on other clinical services. A retrospective analysis was conducted on all patients who underwent TIOL implantation between November 2016 and January 2019. This retrospective clinical audit was exempt from the UK National Research Ethics Service approval (as per NHS Health Research
Authority guidance) and instead reviewed by a local institutional review board and given approval from the Clinical Effectiveness department of UHPNHST. Permission was given to access patient data, which was anonymised prior to data analysis. The study adhered to the tenets of the Declaration of Helsinki.

LogMAR visual acuity was performed using the Thomson Test Chart 2000 (Thomson Software Solutions, Hatfield, Herts., UK) on patients referred to the cataract service. The pre-operative refractive error was obtained from the subjective refractive prescription by an optometrist or through objective autorefraction. Each patient underwent corneal topography using a Pentacam (Oculus, Wetzlar, Germany) or Topcon KR1W (Topcon, Tokyo, Japan) to rule out irregular corneal astigmatism - a contraindication to TIOL implantation. A Zeiss IOLMaster 700 (Carl Zeiss, Meditec) was used to obtain all other ocular biometry measurements according to the recommendations within the Royal College of Ophthalmologists Cataract Surgery Guidelines 2010 [16]. The Tecnis Toric Aspheric Intraocular lens (model ZCTXXX-Abbot Medical Optics) was used in all cases. This TIOL is a foldable hydrophobic one piece lens made of a mid-index acrylic material (refractive index of 1.47). TIOL power and orientation were chosen by inputting clinical values for axial length, keratometry values ( $K$ values), anterior chamber depth and surgeon-induced astigmatism into the manufacturers' online calculator (TECNIS ${ }^{\circledR}$ IOL Calculator Platform, Abbot Medical Optics).

On the day of surgery, all patients were consented for cataract surgery with TIOL implantation. Alignment of the TIOL was assisted with the aid of the Zeiss Callisto Eye system (Carl Zeiss, Meditec). This is a digitally assisted cataract surgery programme that utilises a pre-operative image (captured with the IOLMaster 700) with relevant biometry data for review in the operating room. The ' $\mathrm{Z}$ Align-Toric assistant' allows the use of reference axes from the IOLMaster and the use of target axis in the microscope eyepiece in order to provide markless alignment of TIOLS. All procedures were performed by a single surgeon (NEH) using a standard surgical approach, which involved a microcoaxial phacoemulsification through a temporal $2.2 \mathrm{~mm}$ clear corneal incision. A manual $5.5 \mathrm{~mm}$ capsulorhexis was performed with the aid of Callisto 'rhexis assistant' and a conventional 'stop and chop' technique was used. The capsular bag was inflated with an ophthalmic viscosurgical device (Healon-Abbott Medical Optics). A polymethyl methacrylate capsular tension ring (Ophtec) was inserted to provide additional IOL rotational stability. The Tecnis TIOL was injected and aligned with the marked steep meridian, as assisted by the Callisto system (Fig. 1). Healon was aspirated from inside the capsular bag, taking care to remove any remnants from behind the IOL. The IOL position was rechecked after the anterior chamber was 


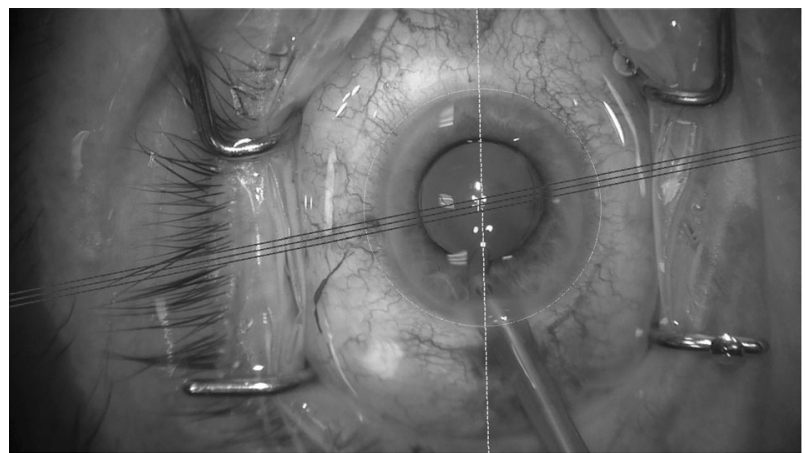

Fig. 1 TIOL alignment on the visual axis provided by IOL master with the Callisto Eye system (Carl Zeiss, Meditec).

reformed and intracameral cefuroxime $1 \mathrm{mg} / 0.1 \mathrm{ml}$ (Aprokram-Thea Pharmaceuticals) was administered. Post-operatively all patients received Dexamethasone $0.1 \%$ / Neomycin $0.35 \%$ eye drops (Maxitrol-Novaratis Pharmaceuticals) to the operated eye for 4 weeks. All patients attended a post-operative check on day 1 and at 4 weeks.

Outcome measures such as pre- and post-operative visual acuities (unaided and best corrected), refractions (obtained either by manifest subjective refraction or autorefraction) and all complications were recorded on Medisoft (Heidelberg Engineering $\mathrm{GmbH}$ ). The minimum follow-up of postimplantation refractive outcomes was 4 weeks. The predicted spherical equivalent (SE) following TIOL implantation was compared with the post-operative refraction. Vector analysis was used to calculate surgically induced refractive correction (SIRC), correction ratio (CR), error magnitude (EM) and error vector (EV).

\section{Results}

\section{Patient demographics}

Sixty-six eyes of forty-seven participants were included in the analysis for the study. $47 \%$ of participants were male and the cohort had an average age of $73.8 \pm 12.3$ years. Patients with ocular co-morbidities were included (Table 1). The magnitude of pre-operative corneal keratometric cylinder ranged from 3.00 to $12.00 \mathrm{DC}$ and the magnitude of pre-operative refractive cylinder ranged from 1.50 to 10.25DC (Table 2; Fig. 2a).

\section{Mean spherical refraction}

The mean post-operative mean SE refractive error was $-0.38 \pm 0.69 \mathrm{D}$, whilst the target SE was $-0.33 \pm 0.19 \mathrm{D}$. The mean accuracy of the SE refractive error was $-0.08 \pm$ $0.64 \mathrm{D}$ with $94 \%$ within $\pm 1.00 \mathrm{D}$ of the target refraction and $62 \%$ within $\pm 0.50 \mathrm{D}$ (Fig. 2 b).
Table 1 Ocular co-morbidities.

\begin{tabular}{|c|c|}
\hline Co-morbidities & Number of eyes affected \\
\hline Retinal & $\begin{array}{l}\text { Dry age-related macular degeneration-13 } \\
\text { Retinoschisis }-1\end{array}$ \\
\hline Neuro-ophthalmology & $\begin{array}{l}\text { Abducens nerve palsy-1 } \\
\text { Chronic external ophthalmoplegia-1 }\end{array}$ \\
\hline Corneal & $\begin{array}{l}\text { Fuchs endothelial dystrophy-2 } \\
\text { Corneal scarring-1 } \\
\text { Previous keratoplasty }-2\end{array}$ \\
\hline Glaucoma & $\begin{array}{l}\text { Chronic narrow angle-2 } \\
\text { Chronic open angle }-4\end{array}$ \\
\hline Other & $\begin{array}{l}\text { Amblyopia-7 } \\
\text { High myopia-7 } \\
\text { Nanophthalmos-2 }\end{array}$ \\
\hline
\end{tabular}

\section{Visual acuity}

The mean post-operative unaided vision was $0.25 \pm 0.189$ LogMAR with $\sim 30 \%$ of patients able to resolve $0.1 \mathrm{Log}$ MAR or better (Fig. 2c) with two thirds of patients within European driving standards unaided (0.3 LogMAR).

\section{Astigmatic correction}

The mean absolute magnitude of pre-operative corneal astigmatism and refractive cylinder was $4.39 \pm 1.69 \mathrm{D}$ (Fig. 2a) and $4.69 \pm 1.77 \mathrm{D}$ (Fig. 2d). Following TIOL implantation the average absolute magnitude of refractive astigmatism reduced to $1.34 \pm 1.07 \mathrm{D}$.

The mean absolute magnitude of targeted astigmatic change was $3.74 \pm 0.90 \mathrm{D}$ (Fig. 2e), whilst the actual achieved astigmatic change was $4.14 \pm 1.39 \mathrm{D}$ (Fig. 2f). This demonstrated a slight overcorrection that increased as the target change increased (Fig. 2g). The actual astigmatic magnitude change was within 0.50DC of the target astigmatic magnitude change in $36 \%$ of cases, within $1.00 \mathrm{DC}$ in $68 \%$ of cases, and within 1.50DC in $88 \%$ of cases (Fig. $2 \mathrm{~g}$ ).

The results of the CR highlights a slight overcorrection when examining the total group $(1.10 \pm 0.26)$. The eyes were then categorised as with-the-rule (within 20 degrees of vertical; 37 eyes), against-the-rule (within 20 degrees of horizontal; 19 eyes) or oblique (10 eyes). The CR were significantly different for the different categorisations (withthe-rule $1.20 \pm 0.22$; against-the-rule $0.97 \pm 0.27$; oblique $0.99 \pm 0.29)\left(\mathrm{F}_{6.876}, p=0.002\right)$ and analysis with the Tukey post hoc test revealed an overcorrection of the with-the-rule eyes in comparison with both the against-the-rule $(p=$ 0.004 ) and the oblique eyes ( $p=0.45)$ (Fig. $2 \mathrm{j}$ ).

The absolute magnitude of the difference vector $(1.27 \pm$ $0.72 \mathrm{D})$ was relatively small given the overall magnitude of astigmatic change (Fig. 2i) with the refractive astigmatism 
Table 2 Pre-operative corneal and refractive data.

\begin{tabular}{llll}
\hline & & Mean & Range \\
\hline Pre-operative refractive & Mean spherical equivalent & $-0.83 \pm 5.00 \mathrm{D}$ & -13.13 to $+8.50 \mathrm{D}$ \\
& $\mathrm{J} 0$ & $-0.83 \pm 4.39 \mathrm{D}$ & -8.88 to $+8.32 \mathrm{D}$ \\
& $\mathrm{J} 45$ & $-0.27 \pm 2.17 \mathrm{D}$ & -4.97 to $+6.89 \mathrm{D}$ \\
Pre-operative visual acuity & & $0.52 \pm 0.28$ LogMAR & $0.18-1.6$ LogMAR \\
Pre-operative corneal & Absolute keratometric & $4.38 \pm 1.69 \mathrm{D}$ & $3.00-12.00 \mathrm{D}$ \\
astigmatism & cylinder power & & \\
& J0 & $-0.96 \pm 4.15$ & $-6.89-11.53 \mathrm{D}$ \\
& J45 & $-0.17 \pm 2.06$ & $-4.95-5.08 \mathrm{D}$ \\
\hline
\end{tabular}

angle of error greater than 15 degrees in only $8 \%$ of eyes (Fig. 2j).

\section{Discussion}

This is the first study to evaluate the outcomes of TIOL implantation, specifically in subjects with both high corneal astigmatism and ocular co-morbidities, as part of a defined care pathway within an NHS trust. The results highlight the effectiveness of TIOL correction within this population as demonstrated by a surprisingly accurate correction index of $(1.10 \pm 0.26)$. In a randomised controlled trial conducted by Holland et al. [17] $90 \%$ of subjects implanted with a TIOL had a residual refractive cylinder of $1.00 \mathrm{DC}$ or less. In comparison, the mean residual astigmatism in our study was $1.34 \pm 1.07 \mathrm{DC}$. This can be attributed to the fact that a residual refractive astigmatic error was expected given that emmetropia was not the target in all cases. The expected post-operative residual astigmatism ranged from 0.01 to $6.84 \mathrm{DC}(0.65 \pm 1.09 \mathrm{DC})$. Uncorrected visual acuity was also lower, which is attributed to the presence of ocular comorbidities. As such, these findings would be representative of a typical NHS cohort; which may make our results potentially applicable to trusts all over the UK.

Studies evaluating the efficacy of TIOL in high corneal astigmatism are relatively sparse and it is difficult to compare results given differences in methodologies. Alio et al. [18] conducted a prospective study examining the effectiveness of TIOL in 21 eyes with corneal astigmatism $>2.25 \mathrm{D}$. In this study a slight under correction was achieved (target astigmatic change: $4.54 \pm 2.72 \mathrm{D}$; Achieved astigmatic change: $4.18 \pm 1.39$ ) as reflected by the correction index $(0.91 \pm 1.23)$. Both the post-operative vision $(0.65 \pm$ 0.22 decimal $)$ and refractive astigmatic cylinder $(0.45 \pm$ $0.63 \mathrm{DC})$ were better than those in the present study. However, this discrepancy can be explained by the fact that the authors excluded co-morbidities and that the expected residual refractive cylinder was lower than in the present study. Similarly, Entabi et al. [19] evaluated the use of Tflex TIOL in a prospective study on 33 eyes with corneal astigmatism $>2.00 \mathrm{DC}$. The mean pre-operative refractive cylinder of $2.94 \pm 0.91 \mathrm{D}$ was lower in the Entabi study, as was the target residual astigmatism. As such, it is expected that these subjects would achieve better-unaided visual acuity and lower overall residual refractive astigmatism. However, the study did not report the astigmatic outcomes according to the standardized vector analysis first described by Alpins [20-22], making it difficult to understand the nuances of the astigmatic correction achieved in this study. Similarly, this type of reporting is only partially utilised in the study by Visser et al. [23] which examined the use of four AcrySof TIOLs in 67 eyes with corneal astigmatism greater than 2.25DC (mean pre-operative cylinder $4.02 \pm$ 1.28DC). In concurrence with the present study, Visser et al. included eyes with ocular co-morbidities finding comparable mean residual refractive cylinder and achieved astigmatic change $4.14 \pm 1.39 \mathrm{DC}$.

Our results demonstrated a significantly greater overcorrection in eyes categorised as having with-the-rule astigmatism. This can be explained by the work of Koch et al. who demonstrated that corneal power is overestimated in cases of with-the-rule astigmatism, when only the anterior surface of the cornea is assessed. They proposed that the cornea should be assessed using a method that includes posterior corneal curvature evaluation. If a device that calculates corneal astigmatism from the anterior corneal surface is used, then the results should be adjusted using a nomogram [24].

Residual astigmatism significantly impacts on patients' visual acuity after cataract surgery [25]. Astigmatic correction during cataract surgery enables the possibility of spectacle independence at distance. For the patient, the benefits are not only economic [26] but also practical. Spectacle correction of astigmatism creates a meridional magnification, which when coupled with the associated back vertex distance, produces retinal images that are both asymmetrically magnified and distorted. The images produced can decrease spatial perception [27] with adaptation being particularly challenging in the elderly population [28]—in whom the burden of cataract is prevalent. The correction of corneal astigmatism during cataract surgery, brings an important advantage in that no significant meridional 
a

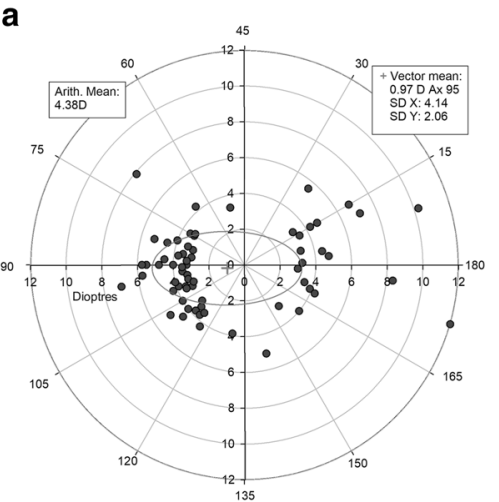

d

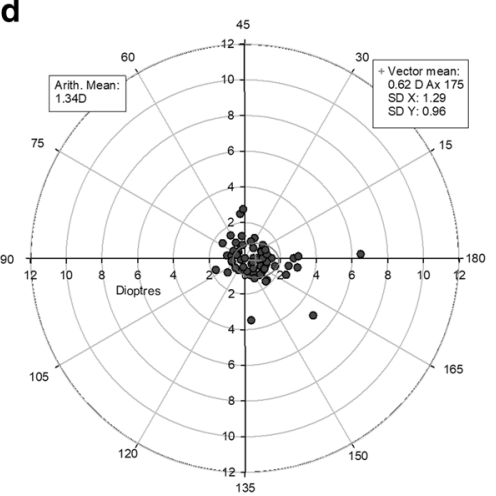

g

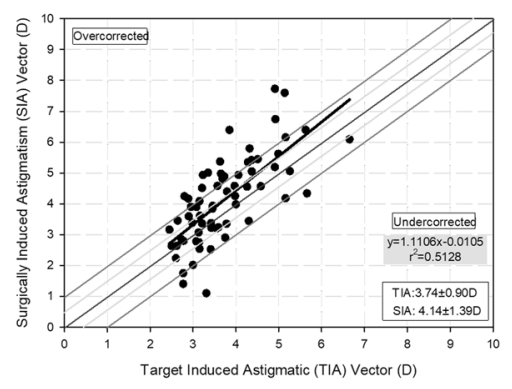

b
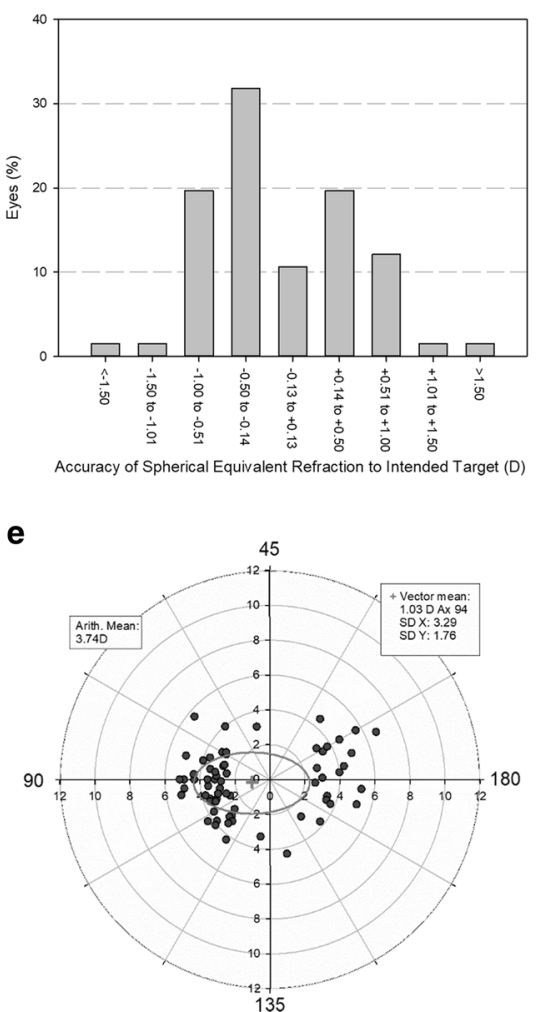

h

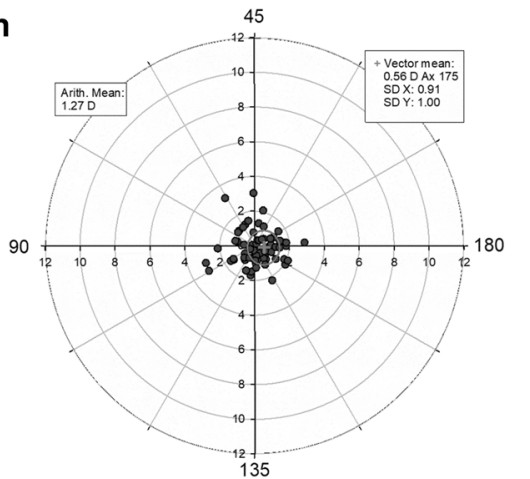

j

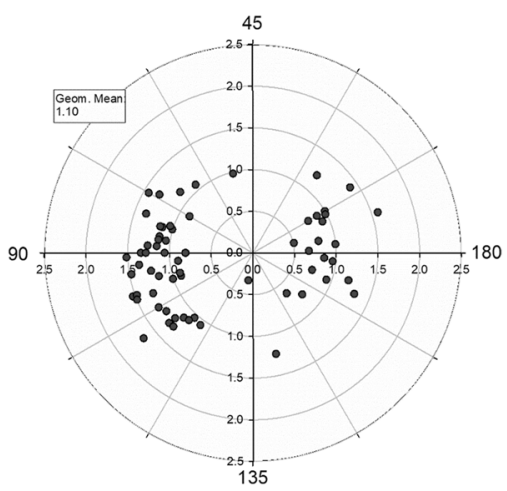

c

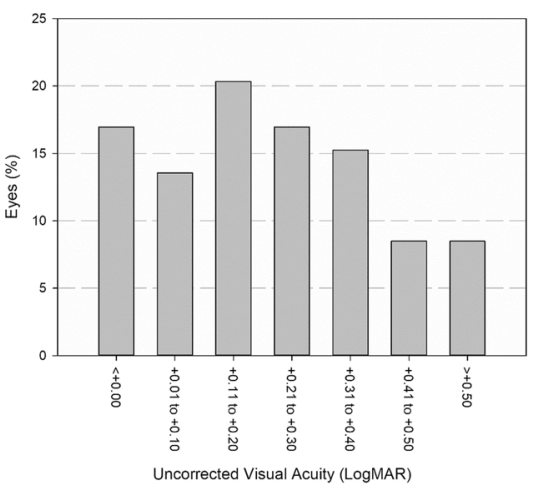

f

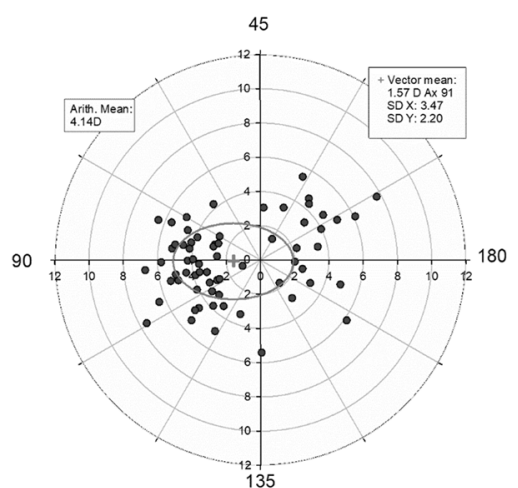

i

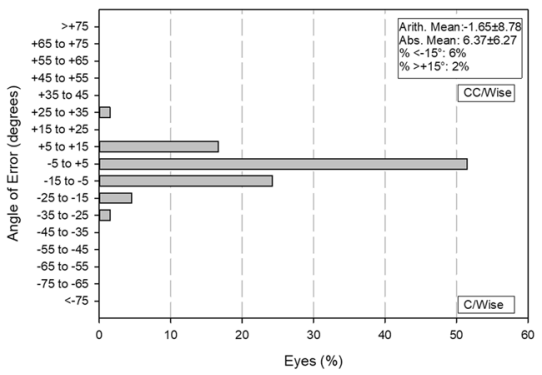

Fig. 2 a Pre-operative corneal keratometric astigmatism. b Spherical equivalent refractive accuracy. c Post-operative unaided visual acuity. d Post-operative refractive astigmatism. e Intended refractive correction. f Surgically induced astigmatism vector. g Intended refractive correction compared with surgically induced refractive correction. h Error vector. i Refractive astigmatism angle of error. j Correction index. 
magnification is induced due to a negligible vertex distance [29]. An additional benefit is the dispensation of low visual aids in patients undergoing cataract surgery with TIOL, is potentially made more efficacious in patients with macular degeneration or other retinal pathologies.

\section{Conclusion}

We believe that our results may offer evidence for this visually rehabilitating treatment to those with pre-existing compromised vision and hopefully resulting in a better quality of life. Previous studies often excluded patients with pre-existing ocular co-morbidities; leaving a paucity of evidence based management of these individuals, who constitute a considerable population undergoing cataract surgery in the UK. The cost-benefit analysis of the widespread use of these IOLs may potentially outweigh the use topography and need for IOL realignment but this requires further inquiry. In conclusion, the results demonstrate the efficacy of TIOL implantation in patients with high corneal astigmatism and provide further evidence advocating their use in cataract surgery within NHS hospital eye services.

\section{Summary}

\section{What was known before}

- There is a significant burden of pre-operative astigmatism in the UK cataract population. Toric intraocular lenses (TIOLs) are effective in the neutralisation of corneal astigmatism at the time of cataract surgery.

\section{What this study adds}

- Implantation of the TIOLs during cataract surgery is effective in correcting high amounts of corneal astigmatism, particularly in patients with ocular comorbidities. Reduced cylindrical correction and improved unaided visual acuity provide good cases for use of TIOLs in selected patients undergoing cataract surgery in a public health setting.

\section{Compliance with ethical standards}

Conflict of interest The authors declare that they have no conflict of interest.

Publisher's note Springer Nature remains neutral with regard to jurisdictional claims in published maps and institutional affiliations.

\section{References}

1. Donachie J, Sparrow JM, Johnston RL. Year 1 annual reportpiloting of the national ophthalmology database audit methodology national ophthalmology database audit. 2016. https://www. nodaudit.org.uk/u/docs/20/thsumcnchv/NOD\%20Audit\% 20Annual\%20Report\%202016.pdf. Accessed 2nd July 2019.

2. Day AC, Dhariwal M, Keith MS, Ender F, Perez Vives C, Miglio $\mathrm{C}$, et al. Distribution of preoperative and postoperative astigmatism in a large population of patients undergoing cataract surgery in the UK. Br J Ophthalmol. 2018;103:993-1000.

3. Ferrer-Blasco T, Montés-Micó R, Peixoto-de-Matos SC, González-Méijome JM, Cerviño A. Prevalence of corneal astigmatism before cataract surgery. J Cataract Refract Surg. 2009;35: $70-5$.

4. Wolffsohn JS, Bhogal G, Shah S. Effect of uncorrected astigmatism on vision. J Cataract Refract Surg. 2011;37:454-60.

5. Wilkins MR, Allan B, Rubin G, Moorfields IOL. Study Group MIS. Spectacle use after routine cataract surgery. Br J Ophthalmol. 2009;93:1307-12.

6. Pineda R, Denevich S, Lee WC, Waycaster C, Pashos CL. Economic evaluation of toric intraocular lens: a short- and long-term decision analytic model. Arch Ophthalmol. 2010;128:834-40.

7. Akura J, Kaneda S, Hatta S, Matsuura K. Controlling astigmatism in cataract surgery requiring relatively large self-sealing incisions. J Cataract Refract Surg. 2000;26:1650-9.

8. Muller-Jensen K, Fisher P, Siepe U. Limbal relaxing incisions to correct astigmatism in clear corneal cataract surgery. J Refract Surg. 1999;15:586-9.

9. Lever J, Dahan E. Opposite clear corneal incision to correct preexisting astigmatism in cataract surgery. J Cataract Refract Surg. 2000;26:803-5.

10. Lindstrom RL, Lindquist TD. Surgical correction of postoperative astigmatism. Cornea. 1988;7:138-48.

11. Ali MA, Abdelhalim AS. Ocular surface changes after simultaneous cataract surgery and limbal relaxing incisions. J Egypt Ophthalmol Soc. 2017;110:28-30.

12. Haripriya A, Smita A. A case of keratitis associated with limbal relaxing incision. Indian J Ophthalmol. 2016;64:936-7.

13. Pepose JS, Hayashida J, Hovanesian J, et al. Safety and effectiveness of a new toric presbyopia-correcting posterior chamber silicone intraocular lens. J Cataract Refract Surg. 2015;41:295-305.

14. Sheppard AL, Wolffsohn JS, Bhatt U, et al. Clinical outcomes after implantation of a new hydrophobic acrylic toric IOL during routine cataract surgery. J Cataract Refract Surg. 2013;39:41-7.

15. National Institute for Health and Care Excellence. Cataracts in adults: management. https://www.nice.org.uk/guidance/ng77/cha pter/Recommendations-for-research\#1-toric-lenses-for-astigma tism. 2017; Accessed 14 July 2019.

16. Royal College of Ophthalmologists. Cataract surgery guidelines. https://www.rcophth.ac.uk/wp-content/uploads/2014/12/2010-SCI069-Cataract-Surgery-Guidelines-2010-SEPTEMBER-2010-1.pdf. 2010; Accessed 14 July 2019.

17. Holland E, Lane S, Horn JD, Ernest P, Arleo R, Miller KM. The AcrySof toric intraocular lens in subjects with cataracts and corneal astigmatism: a randomized, subject-masked, parallel-group, 1-year study. Ophthalmology. 2010;117:2104-11.

18. Alio JL, Agdeppa MCC, Pongo VC, El Kady B. Microincision cataract surgery with toric intraocular lens implantation for correcting moderate and high astigmatism: pilot study. J Cataract Refract Surg. 2010;36:44-52.

19. Entabi M, Harman F, Lee N, Bloom PA. Injectable 1-piece hydrophilic acrylic toric intraocular lens for cataract surgery: efficacy and stability. J Cataract Refract Surg. 2011;37:235-40. 
20. Alpins N. Astigmatism analysis by the Alpins method. J Cataract Refract Surg. 2001;27:31-49.

21. Alpins NA. Vector analysis of astigmatism changes by flattening, steepening, and torque. J Cataract Refract Surg. 1997;23:1503-14.

22. Alpins NA. A new method of analyzing vectors for changes in astigmatism. J Cataract Refract Surg. 1993;19:524-33.

23. Visser N, Ruíz-Mesa R, Pastor F, Bauer NJ, Nuijts RM, MontésMicó R. Cataract surgery with toric intraocular lens implantation in patients with high corneal astigmatism. J Cataract Refract Surg. 2011;37:1403-10.

24. Koch DD, Jenkins RB, Weikert MP, Yeu E, Wang L. Correcting astigmatism with toric intraocular lenses: effect of posterior corneal astigmatism. J Cataract Refract Surg. 2013;39:1803-9.
25. Koch DD, Ali SF, Weikert MP, Shirayama M, Jenkins R, Wang L. Contribution of posterior corneal astigmatism to total corneal astigmatism. J Cataract Refract Surg. 2012;38:2080-7.

26. Laurendeau C, Lafuma A, Berdeaux G. Modelling lifetime cost consequences of toric compared with standard IOLs in cataract surgery of astigmatic patients in four European countries. J Med Econ. 2009;12:230-7.

27. Guyton DL. Prescribing cylinders: the problem of distortion. Surv Ophthalmol. 1977;22:177-88.

28. Ogle KN, Madigan LF. Astigmatism at oblique axes and binocular stereoscopic spatial localization. Arch Ophthalmol. 1945;33:116-27.

29. Novis C. Astigmatism and toric intraocular lenses. Curr Opin Ophthalmol. 2000;11:47-50. 